Lori Barile

\title{
Mobile technologies for libraries
}

A list of mobile applications and resources for development

$\mathbf{T}$

he International Telecommunication

Union (ITU) estimated that more than 5 billion mobile subscriptions would exist worldwide by the end of 2010, which more than tripled home Internet access. ${ }^{1}$ ITU also predicts Web access from mobile devices will exceed access from desktop computers within the next five years. ${ }^{2}$

These statistics are hardly surprising; with advancements in technology and the rise in smartphone use, people are taking advantage of being connected to data wherever they are. Mobile phones aren't just phones anymore: they can access e-mail, search the Web, video chat, and play games. Even mobile devices like iPad and iPod touch can bring social media, productivity tools, and entertainment literally into the palm of your hand.

Therefore, libraries should be exploring mobile devices as a way to connect with patrons. Creating a library application ("app") or mobile Web site that allows patrons to access library hours, view their library account or even search databases is easier than most people think. The resources below should help libraries begin to plan and implement their own unique mobile presence.

Resources were chosen based on relevancy, accuracy, and content. Due to current economic considerations, free mobile applications were chosen over similar paid applications.

\section{History and development of mobile applications and Web sites}

- Libraries to Go: Mobile Tech in Libraries. Comprehensive Slideshare presentation that reviews how libraries can use and develop mobile technologies. Access: http://www.slideshare.net/ellyssa/librariesto-go-mobile-tech-in-libraries-presentation.

- Library in Your Pocket: Strategies and Techniques for Developing Successful Mobile Services. Mobile site developers from North Carolina State University Libraries share techniques for creating and promoting mobile services. Access: http:// www.educause.edu/Resources/LibraryinYourPocketStrategiesa/195003.

- M-Libraries-Library Success: A Best Practices Wiki. Includes listings of libraries that offer mobile Web sites (with and without OPACS) and publishers who offer

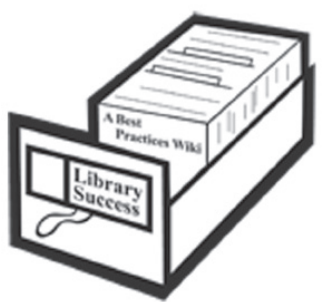
mobile versions of databases. Access: http://libsuccess.org $/$ index.php?title $=$ M-Libraries .

- Spectrum>Mobile Learning, Libraries, and Technologies. This blog documents topics relating to mobile technologies. Posts include information about specific mobile applications as well as their general usage in libraries. Access: http:// mobile-libraries.blogspot.com/.

\section{Mobile applications for learning}

- Classics-23,469 Books to Go. Large collection of free classic literature packaged in an elegant and intuitive interface.

Lori Barile is learning commons librarian at Salve Regina University, e-mail: lori.barile@salve.edu

c 2011 Lori Barile 
Authors include Aristotle, Charles Dickens, Plato, and Oscar Wilde. By Spreadsong, Inc., Classics works with iPhone, iPod touch, and iPad. Price: Free. Access: http:// spreadsong.com.

- Dropbox. Store, sync, and share files online and across computers. Access your Dropbox, download files for offline viewing, and sync photos and videos to your Dropbox from your mobile device. Dropbox works with iPhone, iPad, Android, and BlackBerry. Access: https://www. dropbox.com/anywhere.

- Evernote. Create text, video, and audio memos. All content within Evernote is searchable, including text within snapshots. Notes can be synchronized to Mac, PC, and Web. Evernote works with iPhone, iPod touch, iPad, Android, BlackBerry, Palm, and Windows Mobile. Price: Free. Access: http:// www.evernote.com/about/download/.

\section{EVERNote}

- History: Maps of the World. This app by Seung-Bin Cho showcases highresolution historical maps of the world from the 4 th to the 20th centuries. Features include category/era views and keyword search. History: Maps of the World works with iPhone, iPod touch, and iPad. Price: Free. Access: http://itunes.apple.com/us /app/history-maps-of-world/id303282377.

- iSSRN. Created by the Social Science Research Network (SSRN), iSSRN provides access to more than 260,000 research papers in the social sciences and humanities from scholars worldwide. Articles can be e-mailed or viewed on the device. iSSRN works with iPhone and iPod touch. Price: Free. Access: http://ssrnblog. com/2009/11/19/ssrns-iphone-app-issrn -is-available/.

- Library of Congress (LOC). Official app for LOC offers a virtual tour of the Main Reading Room, Great Hall, and Thomas Jefferson's Library, as well as exhibition highlights. Includes photos, video, and audio. Access: http://itunes.apple.com/us/app /library-of-congress-virtual/id380309745.

- Meebo Mobile. Chat with friends or even monitor your library's chat service while on-the-go. Meebo aggregates multiple chat accounts into a single, easy-to-use interface. Meebo Mobile works with iPhone, Android, and BlackBerry. Access: http:// www.meebo.com/meebomobile/.

- OECD Factbook 2010. Created by the Organization for Economic Co-operation and Development, this app presents current economic, social, and environmental statistics. The data is organized into 12 categories, such as Population and Migration, Production and Income, Labour, Science and Technology, and more. Each category offers a range of specific sub-topics with data organized into tables. OECD Factbook 2010 works with iPhone, iPod touch, and iPad. Price: Free. Access: http://www.oecd. org/publications/factbook.

- Periodic Table Explorer. By Paul Alan Freshney, this app contains in-depth information about all of the elements in the periodic table, including their compounds, physical properties, isotopes, spectra, and reactions. Also includes images of each element. Periodic Table Explorer works with iPhone, iPod touch, and iPad. Price: Free. Access: http://freshney.org/apps/pte.htm.

- Planets. This app by Q Continuum uses current location to display detailed view of the sky. Provides location of the sun, moon, and planets; star and constellation maps; and future and current moon phases. Viewing options such as the sky in 2D, 3D, and planet visibility are available. Planets works with iPhone, iPod touch, and iPad. Price: Free. Access: http://www. qcontinuum.org/planets/.

- Shakespeare. This application by Readdle offers the full-text of 40 Shakespeare plays, 6 poems, and 154 sonnets. Includes a searchable concordance. Shakespeare works with iPhone, iPod touch, and iPad. Price: Free. Access: http://readdle.com /shakespeare. 
- TED. This app by TED Conferences contains the entire TEDTalks library of more than 700 video presentations. Ability to sort by recency, popularity, tags, or themes. Save talks for offline viewing. TED works with the iPad. Price: Free. Access: http:// itunes.apple.com/us/app/ted/id376183339.

- USA Factbook Free. Features facts about all 50 U.S. states, maps with state names, U.S. Anthem with lyrics, U.S. Documents (including the Declaration of Independence), and more. By ADS Software Group, Inc. USA Factbook Free works with iPhone, iPod touch, and iPad. Price: Free. Access: http://itunes.apple.com/us/app /usa-factbook-free/id305888083.

- WordWeb Dictionary. Extensive English dictionary and thesaurus that includes more than 285,000 words, phrases, and derived forms. A separate audio version is also available for $\$ 1.99$. By WordWeb Software, WordWeb Dictionary works with iPhone, iPod touch, and iPad. Price: Free. Access: http://www.wordwebsoftware.com/ WordWebiPhone.html.

\section{Discovering and downloading mobile applications}

- AppBrain. Discover Android apps via search, rankings, and categories. Install apps from the Web with the Fast Web Installer app. Access: http://www.appbrain.com/.

- Appolicious. Browse applications for most mobile devices, including Android and iPhone. Read app reviews and find lists of the best apps. Access: http://www. appolicious.com/.

- App Store. Find applications in categories such as games, business, education, productivity, and entertainment. Apps can be downloaded wirelessly to iPhone, iPod touch, and iPad. Access: http://itunes. apple.com/us/genre/mobile-softwareapplications/.

- App Store HQ. Browse all apps, search by category, read the latest app reviews, and more. The App Store HQ covers Android, iPhone, iPad, and Web apps. Access: http://www.appstorehq.com/.
- Getjar. Browse applications by category or device type. Compatible with most major platforms such as Android, BlackBerry, Windows Mobile, and iPhone. Access: http://www.getjar.com.

- Mimvi. This mobile apps search engine discovers iPhone, Android, and Blackberry apps. Type a category in the text box and Mimvi will return a list of related apps. Icons represent each app's native device. Access: http://www.mimvi.com.

\section{Mobile Web sites}

In addition to or in place of mobile applications, some companies and organizations also develop mobile versions of their Web site that are better optimized for viewing on mobile devices.

- Encyclopedia Britannica Mobile. Offers a search box and a list of suggested searches. Results include full-text entries with enlargeable images. Access: http://i. eb.com/.

- MedlinePlus Mobile. Produced by the U.S. National Library of Medicine, MedlinePlus Mobile provides information about specific diseases, conditions, and wellness issues. The site also contains prescription drug information, medical dictionary, and current health news. Access: http://m.medlineplus.gov.

- WorldCat Mobile. Search the WorldCat catalog for books, movies, music, games, and more. Results include items available at local libraries. Access: http:// www.worldcat.org/m.

\section{S) WorldCat}

\section{Creating mobile Web sites, OPACs, and applications}

- Android Developers. Resources for creating Android applications. Includes developer's guide, tutorials, and videos. Access: http://developer.android.com

- AirPac (Innovative Interfaces). 
Offers a mobile version of the Innovative Interfaces (III) library catalog. Includes features such as cover images, integrated library locations with Google Maps software, request and renew items, and more. Contact Innovative Interfaces for pricing. Access: http://www.iii.com/products /airpac.shtml.

- Boopsie. Specializing in public and academic libraries and universities, Boopsie can deliver mobile applications that are compatible with all Web-enabled phones. Contact the site for a price quote. Access: http://www.boopsie2.com/.

- Create an iPhone Optimised Website using JQTouch. Freelance Web Designer and Developer Matthew Leak outlines one way to create an iPhone-friendly version of a Web site. Coding examples are included in this tutorial. Access: http:// www.tuttoaster.com/create-an-iphone -optimised-website-using-jqtouch/.

- Library Anywhere. Created and sold through LibraryThing, Library Anywhere is a mobile catalog for any library. Includes mobile Web and apps for iPhone, Blackberry, and Android. Prices range from $\$ 150$ annually for schools to $\$ 1,000$ annually for universities (additional fees may apply). Access: http://www.librarything.com forlibraries.

- MobileTuts+. Tutorials for all mobile developers, regardless of platform. Topics include techniques for building mobile apps and mobile Web sites. Access: http://mobile. tutsplus.com/.

- MobiSiteGalore. Build a mobile Web site in less than 60 minutes. No technical or programming knowledge required. Packages range from basic (cost: free) to unlimited (cost: \$24.99 per month). Access: http://www.mobisitegalore.com.

- MoFuse. Build a mobile version of an existing Web site or blog with the MoFuse (short for Mobile Fusion) content management platform. Plans range from $\$ 7.95$ per month to $\$ 199$ per month. All accounts come with a 14-day risk-free trial. Access: http://mofuse.com/.
- Mobile Web Best Practices 1.0: Basic Guidelines. Created by the World Wide Web Consortium (W3C), this document specifies guidelines for developing Webbased content for mobile devices. Access: http://www.w3.org/TR/mobile-bp/.

- w3C MobileOK Checker. Validate mobile-optimized Web sites for compatibility with current Web standards. Results include severity, category, and description of the error along with best practices for fixing issues. Access: http://validator. w3.org.

\section{Examples of mobile library Web sites}

- Adelphi University Libraries Mobile (AU2GO). Offers library hours, library staff contact information, a link to the library's blog "biBLIOGraphy," and more. Access: http://m.adelphi.edu/library/.

- Albertsons Library, Boise State University. Simple text navigation offers various ways to find the library and its contents. An interesting feature is the inclusion of a "Find in Our Building" category, which lists call number locations and popular locations such as study rooms and computers, each linked to an animated floor map. Access: http://library.boisestate.edu/m.

- North Carolina State University (NCSU) Libraries. Elegant interface with icons representing categories such as room reservations, group finder, and Webcams. Another interesting feature is the ability to view the number of available library computers. Access: http://www.lib.ncsu.edu/m /home/?browse=iphone.

- PENNLibraries, University of Pennsylvania. A multitude of information at your fingertips, such as mobile versions of databases, image search, library video clips, and more. Access: http://www.library.upenn. $\mathrm{edu} / \mathrm{m} /$.

- University of California Riverside Libraries. Glossy icons designate many useful categories, including research guides, library workshops, and links to

(continues on page 228) 
from within the collection. It is enjoyable to work with the students and get them excited about the archival aspects of their assignments, however, my ulterior motive is to raise awareness with the students where I think it will be the most productive: the FSU History Department. We have done other things, such as creating a reading room/display area devoted to the resources of the collection. Heritage Protocol is also very involved in the annual Heritage Day celebration, and the current movement to create an FSU History Museum. Again, these all help to engage alumni, and raise awareness within the current student population about the history of their university.

I guess what I want to make clear is that a university archives should be considered more than a warehouse for administrative records, and it offers potential for development in other aspects of engagement for both current students and alumni. If one defines the university archives as simply the repository that holds the administrative records of the institution, then my alma mater's university librarian was correct, and there is probably no need for a university archivist at this time. But, if one believes that there is more to it and that there should be an active/aggressive effort to acquire materials from former students that document their experiences at the school, then a university archivist is needed. And if, "not now," I would say, "then when?" In 10 years, 20 years, or another 50 years?

For FSU, our first 50 years are essentially the dark ages of our history. We have virtually no records from that era. And we have no idea what it was like to be a student on the "campus" at that time. We have little insight as to what the students did for fun or what the routine of college life was like. And the unfortunate fact of the matter is once records and artifacts from bygone eras are lost, they are gone forever. In our position now, we cannot redouble our efforts and work extra hard to recoup our losses because it is too late.

So, if my undergraduate alma mater chooses to wait another 10, 20, or 50 years to begin an aggressive campaign to document its cultural history, how much of its history will be lost? How many attics in the region have university-related materials sitting in them? How much has already been thrown away? And how much will be thrown away by the time the university archivist position is created?

I can tell you from experience that FSU waited way too long to care about its history. I am now just trying to play catch-up and save what remains. Let us hope that my undergraduate alma mater does not make the same mistake. $\boldsymbol{n}$

("Mobile technologies for libraries" continued from page 225)

the library's social media profiles. Access: http://m.library.ucr.edu.

- Virginia Tech University Libraries. A simple but effective layout offers important information, such as library hours, contact information, catalog search, and library maps. Access: http://m.lib.vt.edu/.

\section{Notes}

1. International Telecommunications Union, Market Information and Statistics Division Telecommunication Development Bureau, "ITU estimates two billion people

online by end 2010," news release, October 19, 2010, International Telecommunications Union, www.itu.int/net/pressoffice/ press_releases/2010/39.aspx (accessed March 9, 2011).

2. International Telecommunications Union, Market Information and Statistics Division Telecommunication Development Bureau, "ITU sees 5 billion mobile subscriptions globally in 2010," news release, February 15, 2010, International Telecommunications Union, www.itu.int /net/pressoffice/press_releases/2010/06. aspx (accessed March 9, 2011). $\boldsymbol{n}$ 